\title{
Prémio Luso-Espanhol de Química
}

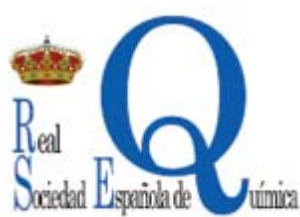

O Prémio Luso-Espanhol de Química, instituído pela Sociedade Portuguesa de Química e pela Real Sociedad Española de Química, é atribuído anualmente, e em alternância, a químicos portugueses e espanhóis com projecção internacional.

Em 2010, ano de início do Prémio, este foi atribuído pela RSEQ ao Prof. José Cavaleiro da Universidade de Aveiro. Em 2011 será a vez da SPQ atribuir pela primeira vez o Prémio a um químico espanhol.

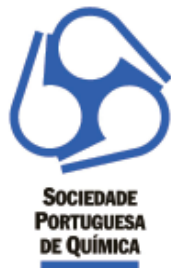

Regulamento do Prémio Luso-EsPANHOL DE QUíMICA

$1^{\circ}$ A Sociedade Portuguesa de Química e a Real Sociedad Española de Química instituem um Prémio LusoEspanhol de Química, que será designado por Conferência LourençoMadinaveitia quando atribuído pela SPQ, e Conferencia MadinaveitiaLourenço quando atribuído pela RSEQ. Esta escolha destina-se a recordar dois químicos notáveis: Agostinho Vicente Lourenço (1822-1893) e Antonio San Quintín Madinaveitia y Tabuyo (1890-1974).

$2^{\circ}$ O Prémio Luso-Espanhol de Química tem como principal objectivo reconhecer investigação científica com projecção internacional realizada em Portugal e Espanha no domínio da Química, em qualquer das suas áreas.

\section{Nota Biográfica do Professor José Cavaleiro}

José A.S. Cavaleiro é Licenciado em Ciências Físico-Químicas pela Universidade de Coimbra, doutorado em Química Orgânica pela Universidade de Liverpool (Robert Robinson Labo-

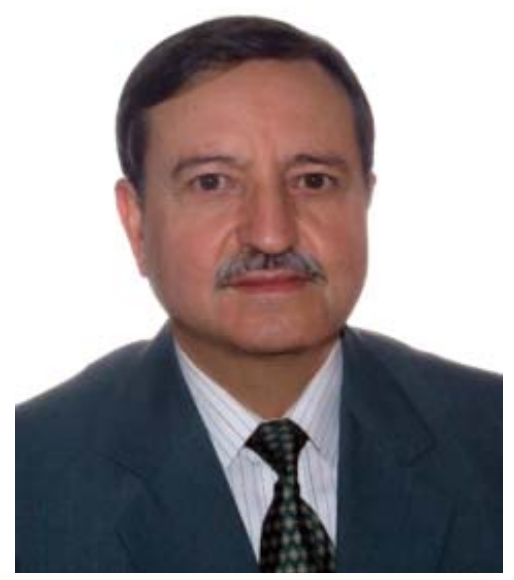

$3^{\circ}$ O Prémio é atribuído anualmente e de forma alternada pelas duas sociedades.

$4^{\circ} \mathrm{A}$ escolha do premiado cabe à sociedade que atribui o prémio.

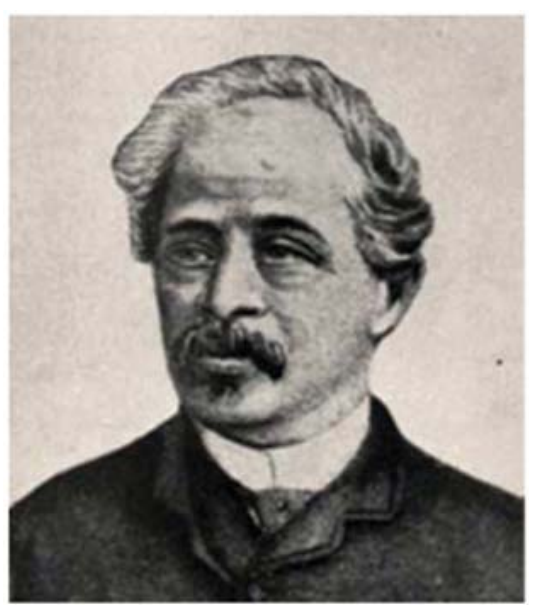

Agostinho Lourenço (1822-1893)

ratories) e tem Agregação em Química conferida pela Universidade de Aveiro. A sua carreira académica foi iniciada como Assistente nas Universidades de Coimbra e de Lourenço Marques (Moçambique), e posteriormente foi Professor Auxiliar e Associado na Universidade de Aveiro, instituição onde é, desde 1986, Professor Catedrático. Está na Universidade de Aveiro sensivelmente desde o início da mesma. Aí desempenhou vários cargos, desde o de Presidente do Departamento de Química e o de Coordenador da Comissão Científica departamental. Teve a responsabilidade de planear, especialmente na fase inicial, o grupo de Química Orgânica, desde a selecção dos membros até às actividades científicas a desenvolver. Tem sido orientador de estudantes de mestrado e de doutoramento e responsável por investigadores pós-doutorados. $5^{\circ}$ O Prémio consiste num diploma, num montante simbólico (500 a 1000 euros) e numa série de conferências (num mínimo de 3) em Universidades e Centros de Investigação do país da sociedade que atribui o prémio.

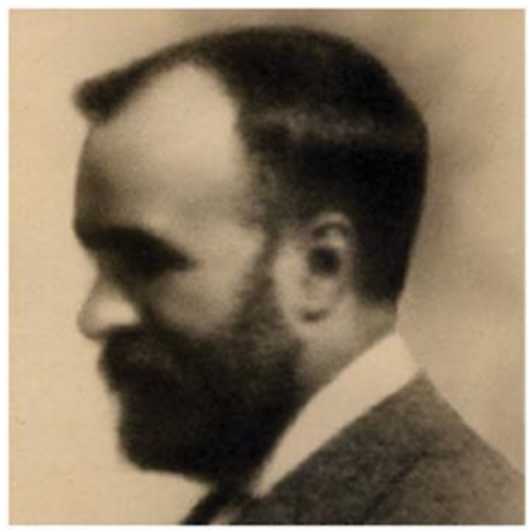

António Madinaveitia (1890-1974)

É o Coordenador da Unidade de Investigação em Química Orgânica, Produtos Naturais e Agroalimentares, unidade financiada pelo Ministério da Ciência, Tecnologia e Ensino Superior (MCTES). Esta unidade, nas avaliações internacionais determinadas pelo MCTES, foi classificada de "Muito Bom" e, na sua última avaliação, de "Excelente".

O Prof. J.A.S. Cavaleiro recebeu os seguintes prémios científicos:

1973: Prémio Parke-Davis nos Robert Robinson Laboratories, University of Liverpool, UK, pelo melhor colóquio de investigação em Química Orgânica de entre os estudantes seus colegas de doutoramento.

2004: Prémio Ferreira da Silva, Sociedade Portuguesa de Química.

2004: Prémio Estímulo à Excelência, Ministério da Ciência e Tecnologia. 
2005: Prémio Celestino da Costa/ Jean Perrin, Embaixada da França em Lisboa, APDF.

2010: Prémio Hispano-Português atribuído pela Real Sociedade Espanhola de Química.

Em Dezembro de 2009 foi eleito para a Academia de Ciências de Lisboa e para a Academia Brasileira de Ciências.

O Prof. J.A.S. Cavaleiro tem sido convidado a proferir conferências em vários congressos internacionais. Presentemente pertence ao "comité" científico internacional da série "European Colloquium on Heterocyclic Chemistry". Tem sido membro de várias sociedades científicas de Química e pertenceu ao "editorial board" durante 10 anos da revista European Journal of Organic Chemistry. Tem sido solicitado para "referee" de várias revistas internacionais de Química. O Prof. J.A.S. Cavaleiro foi o representante português no Programa Ibero-Americano CYTED, rede $4 A$, no Programa COST (acções D2 and D12) e na Comissão IUPAC de Química Orgânica Física (1992-1997).

O Prof. J.A.S. Cavaleiro tem dado ênfase especial às colaborações internacionais no âmbito de projectos de interesse dos grupos envolvidos. Nos últimos dez anos a sua colaboração com grupos brasileiros tem sido bastante produtiva em termos de publicações científicas conjuntas e de intercâmbio de docentes. Além disso, há presentemente cinco jovens professores de Universidades brasileiras que tiveram estágios de doutoramento e pós-doutoramento em Aveiro. Os seus interesses científicos centram-se na área de síntese orgânica, em particular no desenvolvimento de metodologias de síntese de macrociclos porfirínicos e de outros heterociclos de tipo flavonóide, uns e outros satisfazendo requisitos estruturais para serem potenciais candidatos em avaliações de propriedades medicinais (p.e., terapia fotodinâmica de neoplasias, fotoinactivação de micro-organismos). Os estudos de síntese e reactividade de porfirinas, especialmente aqueles envolvendo transformações de cicloadição, desenvolvidos em Aveiro, são reconhecidos a nível mundial, através das diversas publicações nas revistas da especialidade e também dos artigos de revisão e capítulos de livros que, por convite, têm sido publicados. Até ao momento presente é autor de 315 publicações e de 3 patentes.

\section{Final das OLIMPíAdAs de Química.mals 2010}
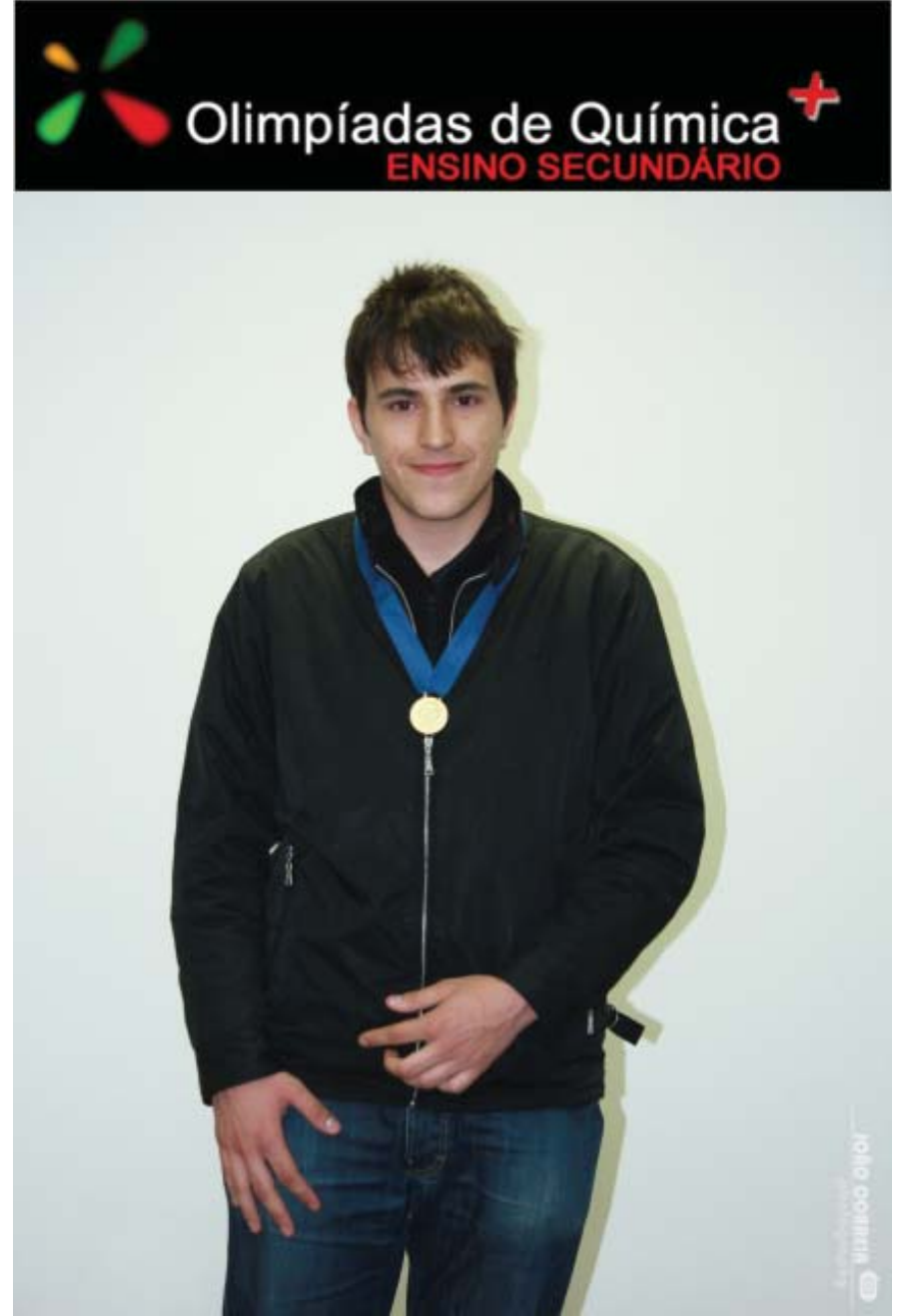

Bernardo Pascoal Figueiredo da ES de D. Inês de Castro (Alcobaça) - vencedor da edição de 2010 das Olimpíadas de Química.mais
Com a realização da Final das Olimpíadas de Química.mais no dia 8 de Maio, no Departamento de Química da Universidade de Aveiro, terminou a edição de 2010 das Olimpíadas Portuguesas de Química. À data da publicação deste número do QUíMICA, faltará ainda realizar a Olimpíada Ibero-americana de Química, no México, onde Portugal está representado pelos jovens seleccionados em 2009.

Tal como é tradição, depois das provas teóricas em equipa que caracterizam as fases anteriores, na Final, os alunos realizam duas provas individuais, uma teórica e outra laboratorial. O tema da prova laboratorial deste ano foi uma titulação ácido-base, para a qual nem todos os alunos se mostraram preparados...

Os vencedores absolutos das Olimpíadas Portuguesas de Química, edição de 2010, foram:

Medalha de Ouro

Bernardo Pascoal Figueiredo

ES de D. Inês de Castro (Alcobaça)

Medalha de Prata

Gonçalo Veríssimo

Externato João Alberto Faria (Arruda dos Vinhos) 